\title{
Changes in extratropical storm track cloudiness 1983-2008: observational support for a poleward shift
}

\author{
Frida A-M. Bender • V. Ramanathan • \\ George Tselioudis
}

Received: 7 January 2011/Accepted: 28 March 2011/Published online: 30 April 2011

(C) Springer-Verlag 2011

\begin{abstract}
Climate model simulations suggest that the extratropical storm tracks will shift poleward as a consequence of global warming. In this study the northern and southern hemisphere storm tracks over the Pacific and Atlantic ocean basins are studied using observational data, primarily from the International Satellite Cloud Climatology Project, ISCCP. Potential shifts in the storm tracks are examined using the observed cloud structures as proxies for cyclone activity. Different data analysis methods are employed, with the objective to address difficulties and uncertainties in using ISCCP data for regional trend analysis. In particular, three data filtering techniques are explored; excluding specific problematic regions from the analysis, regressing out a spurious viewing geometry effect, and excluding specific cloud types from the analysis. These adjustments all, to varying degree, moderate the cloud trends in the original data but leave the qualitative aspects of those trends largely unaffected. Therefore, our analysis suggests that ISCCP data can be used to interpret regional trends in cloudiness, provided that data and instrumental artefacts are recognized and accounted for. The variation in magnitude between trends emerging from application of different data correction methods, allows us to estimate possible ranges for the observational changes. It is found that the
\end{abstract}

F. A-M. Bender $(\bowtie) \cdot$ V. Ramanathan

Center for Clouds, Chemistry and Climate (C4),

Scripps Institution of Oceanography, University of California,

San Diego, La Jolla, CA, USA

e-mail: fbender@ucsd.edu

G. Tselioudis

NASA Goddard Institute for Space Studies,

Columbia University, New York, NY, USA storm tracks, here represented by the extent of the midlatitude-centered band of maximum cloud cover over the studied ocean basins, experience a poleward shift as well as a narrowing over the 25 year period covered by ISCCP. The observed magnitudes of these effects are larger than in current generation climate models (CMIP3). The magnitude of the shift is particularly large in the northern hemisphere Atlantic. This is also the one of the four regions in which imperfect data primarily prevents us from drawing firm conclusions. The shifted path and reduced extent of the storm track cloudiness is accompanied by a regional reduction in total cloud cover. This decrease in cloudiness can primarily be ascribed to low level clouds, whereas the upper level cloud fraction actually increases, according to ISCCP. Independent satellite observations of radiative fluxes at the top of the atmosphere are consistent with the changes in total cloud cover. The shift in cloudiness is also supported by a shift in central position of the mid-troposphere meridional temperature gradient. We do not find support for aerosols playing a significant role in the satellite observed changes in cloudiness. The observed changes in storm track cloudiness can be related to local cloud-induced changes in radiative forcing, using ERBE and CERES radiative fluxes. The shortwave and the longwave components are found to act together, leading to a positive (warming) net radiative effect in response to the cloud changes in the storm track regions, indicative of positive cloud feedback. Among the CMIP3 models that simulate poleward shifts in all four storm track areas, all but one show decreasing cloud amount on a global mean scale in response to increased $\mathrm{CO}_{2}$ forcing, further consistent with positive cloud feedback. Models with low equilibrium climate sensitivity to a lesser extent than higher-sensitivity models simulate a poleward shift of the storm tracks. 


\section{Introduction}

As an integral part of the general circulation of the atmosphere, the regions of large baroclinic wave activity in the mid-latitudes of both hemispheres act to transport heat, moisture and momentum polewards. This results in bands of travelling low pressure systems, with maxima in eddy kinetic energy as well as cloudiness and precipitation in the mid-latitudes, constituting the extratropical storm tracks. In addition to their importance for the general circulation and the local weather, the storm tracks also play a role in climate through large negative radiative forcing [Ramanathan et al. (1989)], and through interrelation with large-scale patterns of climate variability such as the North Atlantic Oscillation (NAO) and El Niño-Southern Oscillation (ENSO).

It has been suggested that global warming causes a poleward displacement of the extratropical storm tracks [IPCC (2007)]. For instance, Yin (2005), tracing storm tracks by eddy kinetic energy, finds a poleward and upward shift as well as an intensification of the storm tracks, in a multi-model mean of 15 CMIP3 models. With more focus on clouds, Tsushima et al. (2006) find a general poleward shift in the center of cloud water distribution in the southern extratropics in response to increased $\mathrm{CO}_{2}$ forcing in a smaller model ensemble. McCabe et al. (2001) and Fyfe (2003) demonstrate poleward shifts in re-analysis data in the northern hemisphere $(\mathrm{NH})$ and the southern hemisphere (SH) storm tracks respectively, and Wang et al. (2006) in both hemispheres using sea level pressure minima to detect cyclones. Further model support for poleward displacement of the storm tracks under greenhouse gas forcing is given by e.g. Hall et al. (1994), Geng and Sugi (2003), Fischer-Bruns et al. (2005) and Bengtsson et al. (2006), using eddy kinetic energy, sea level pressure, surface wind speed and relative vorticity respectively to identify the storm tracks.

In light of these findings we study observations over the past few decades to investigate if and to what extent this displacement can be seen, with a focus on clouds and their radiative effects. We distinguish between four storm track regions; namely those over the $\mathrm{NH}$ Pacific and Atlantic Oceans and the SH Pacific and Atlantic Oceans. We do not discuss the Indian Ocean at all, due to serious shortcomings in the satellite data used. (See further discussion in Sect. 2.1.) As evident in Sect. 2.1 and 3.1, the data for the NH Atlantic must particularly be viewed with caution as well.

The trends in storm track characteristics have previously mainly been studied in model simulations with increasing greenhouse gas concentrations, to accentuate the warming signal, and possibly attribute the shift in storm tracks to anthropogenic forcing. Using the observational record, the signal may be expected to be small, due to weaker forcing. However, the period studied here has seen large global surface temperature increase. The trend is ca $0.02 \mathrm{~K}$ per year, or ca $0.5 \mathrm{~K}$ during the ISCCP period, according to the Hadley Center Climate Research Unit HadCRUT3 data [Brohan et al. (2006)]. This suggests that effects on storm tracks, if present, may already be non-negligible. We illustrate and quantify the changes in storm track cloudiness in Sect. 3.1, and discuss resulting cloud radiative forcing effects in Sect. 3.2. The results are compared with results from GCM simulations in Sect. 3.3.

The shifts of the storm tracks are proposed to be due primarily to changes in vertical and meridional temperature distribution following increased greenhouse gas forcing, but the mechanisms are not yet well known in detail. In Sect. 3.5 we discuss consistency with related meteorological parameters. There is also a possibility of aerosol effects on the storm track cloudiness. Specifically, an intensification of $\mathrm{NH}$ Pacific storm tracks due to Asian pollution has previously been suggested [Zhang et al. (2007)]. This is further addressed in Sect. 3.4.

Data utilized are described in Sect. 2. Satellite data, particularly the ISCCP cloud cover data used, are afflicted with various errors, that may influence the analysis and cause uncertainty. The data must be interpreted with forethought as different ways to account for known data problems may lead to different results for the cloud changes and possible cloud feedbacks. This is further discussed in Sect. 2.1.

\section{Data}

We use the visible/IR detected cloud fraction of the ISCCP (International Satellite Cloud Climatology Project) D2 data set [Rossow and Schiffer (1991), Rossow and Schiffer (1999)], with monthly mean global coverage from July 1983 to June 2008 on a $2.5^{\circ} \times 2.5^{\circ}$ grid. The ISCCP cloud climatology is based on 3-hourly data from a number of geostationary and polar orbiting satellites, calibrated as described by Brest et al. (1997). Clouds are classified as low (cloud top pressure $>680 \mathrm{hPa}$ ), middle $(440 \mathrm{hPa}<$ cloud top pressure $<680 \mathrm{hPa}$ ) and high (cloud top pressure $<440 \mathrm{hPa}$ ), and further into different cloud types based on measured optical thickness; the thinnest clouds have optical thickness $<3.6$, medium thick clouds have $3.6<$ optical thickness $<23$ and thick cloud categories have optical thickness $>23$. These classifications result in nine different cloud types. For instance, clouds with cloud top pressure lower than $440 \mathrm{hPa}$ and optical thickness greater than 23 are referred to as deep convective clouds (DCC).

Radiative flux observations from ERBE (Earth Radiation Budget Experiment) [Barkstrom (1984),Barkstrom and 
Smith (1986)] cover part of the ISCCP period. The longest available consistent ERBE record is the WFOV nonscanner Ed3 Rev1 from the ERBS satellite, covering $60^{\circ} \mathrm{S}-$ $60^{\circ} \mathrm{N}$ from January 1985 to December 1999 . These data are corrected for satellite orbit degradation, and are given as 72-day means to eliminate spurious variability due to the precession of the ERBS satellite, on a $10^{\circ} \times 10^{\circ}$ grid. For clear-sky flux estimates we use the S4G monthly mean data set, which is a compilation of data from the ERBS, NOAA9 and NOAA-10 satellites with global coverage November $1984-F e b r u a r y ~ 1990$, and $2.5^{\circ} \times 2.5^{\circ}$ resolution.

CERES (Clouds and the Earth's Energy System) [Wielicki et al. (1996)] ERBE-like processed data (ES4) has global mean scanner data from the Terra satellite from March 2000 to February 2010, with $2.5^{\circ} \times 2.5^{\circ}$ resolution, that we use to complement the ERBE data. We also include CERES SSF Ed2.5 (March 2000-February 2010) data, with $1^{\circ} \times 1^{\circ}$ resolution, from Terra, that are not based on ERBE-algorithms. Both CERES data sets include clear-sky fluxes, but in the finer resolution SSF product the clear-sky data are missing in most of our regions of interest, due to the large fractional cloud cover.

MODIS (Moderate Resolution Imaging Spectroradiometer) [King et al. (1992)] on the Terra satellite supplies additional cloud property information, like several cloud fraction products and cloud water content segregated by water phase. We also make use of MODIS aerosol properties, specifically aerosol optical depth (AOD). MODIS on Terra gives global monthly means on a $1^{\circ} \times 1^{\circ}$ grid from February 2000 to March 2010, i.e. similar to CERES, partly overlapping, and somewhat extending the ISCCP period.

For comparison we also study output from simulations with 20 different GCMs in the CMIP3, the World Climate Research Programme's (WCRP's) Coupled Model Intercomparison Project phase 3 [Meehl et al. (2007)], using simulations where the $\mathrm{CO}_{2}$ concentration increases by $1 \%$ per year, up to a doubling (ca 75 years).

\subsection{ISCCP data problems and possible remedies}

Global mean cloud fraction as given by ISCCP is known to include non-physical trends [Evan et al. (2007), Norris (2000)], and the regional analysis performed here, may also be affected by instrument and retrieval artefacts.

The main causes of spurious changes are related to the satellite viewing zenith angle (VZA). The cloud fraction at a given point will be seen as larger if the VZA is large [Minnis (1989)]. This is especially a problem for thin clouds, as optically thin clouds that are not detected at low VZA may be detected at high VZA. Systematic changes in global (or regional) mean VZA may therefore cause systematic changes in global (or regional) mean cloud fraction. Changes in viewing angle are related to addition, removal or repositioning of geostationary satellites, or temporary coverage by polar orbiting satellites in gaps in geostationary satellite coverage. Increasing number of geostationary satellites has likely caused a spurious decrease in ISCCP global mean cloud cover, as the global mean VZA has become smaller. The correlation between total cloud fraction and $\mu=1 / \cos (V Z A)$ (as given by ISCCP D1 data) for global mean ocean is 0.71. See "Appendix", Fig. 9.

The large VZAs at the seams between adjacent geostationary satellite footprints may themselves cause nonphysical cloud variability, particularly in the tropics, contributing to the partly spurious interannual variability in the global mean total cloud cover [Evan et al. (2007)]. These regions also clearly emerge in empirical orthogonal function analysis of the ISCCP data, or by simply studying the cloud cover trend gridpoint by gridpoint (not shown).

These data problems can be and have been addressed in different ways, as discussed below, and also applied and compared in Sect. 3.1. Neither of the suggested approaches is ideal, and as seen in Sect. 3.1 they give different results for the regional cloud changes.

\subsubsection{Selective regional analysis}

The most straight-forward way to account for the problems related to varying VZA is to exclude regions or gridpoints where the problems are particularly prominent. This approach is taken e.g. by Evan et al. (2007) and Tselioudis et al. (2010), and has the advantage that no additional data manipulation is necessary. The disadvantage is that spuriousness may still be present in the remaining regions of analysis.

The Indian Ocean is located at the seam between METEOSAT and GOES, and did not get proper geostationary coverage by INSAT until 1997. This particularly leads to spurious effects in the ISCCP data in this specific region [Evan et al. (2007)], and therefore we do not include the storm tracks over the Indian Ocean in our analysis at all. For the storm track regions we study, the stationary satellite coverage has been comparatively constant since the beginning of the ISCCP record, and effects of decreasing mean VZA are not expected to be large. Still, there are changes in regional mean VZA that may cause spurious variability in the cloud cover.

From Fig. 2 of Evan et al. (2007) it is clear that most of our NH Atlantic storm track region is such an area, that is seriously affected by spuriousness caused by satellite viewing angle artefacts. As will be seen in Sect. 3.1 this does affect our results and the data for the NH Atlantic are considered less reliable than those for the remaining regions. Figure 2 of Evan et al. (2007) also shows that the 
Fig. 1 Hovmoller plots of ISCCP total cloud fraction July 1983 to June 2008 for the four storm track regions NH Pacific (upper left), NH Atlantic (upper right), SH Pacific (lower left) and SH Atlantic (lower right). Only ocean data are considered. The black lines show the best-fit straight line to the $85 \%$-cloud fraction isoline on either side of the cloud fraction maximum
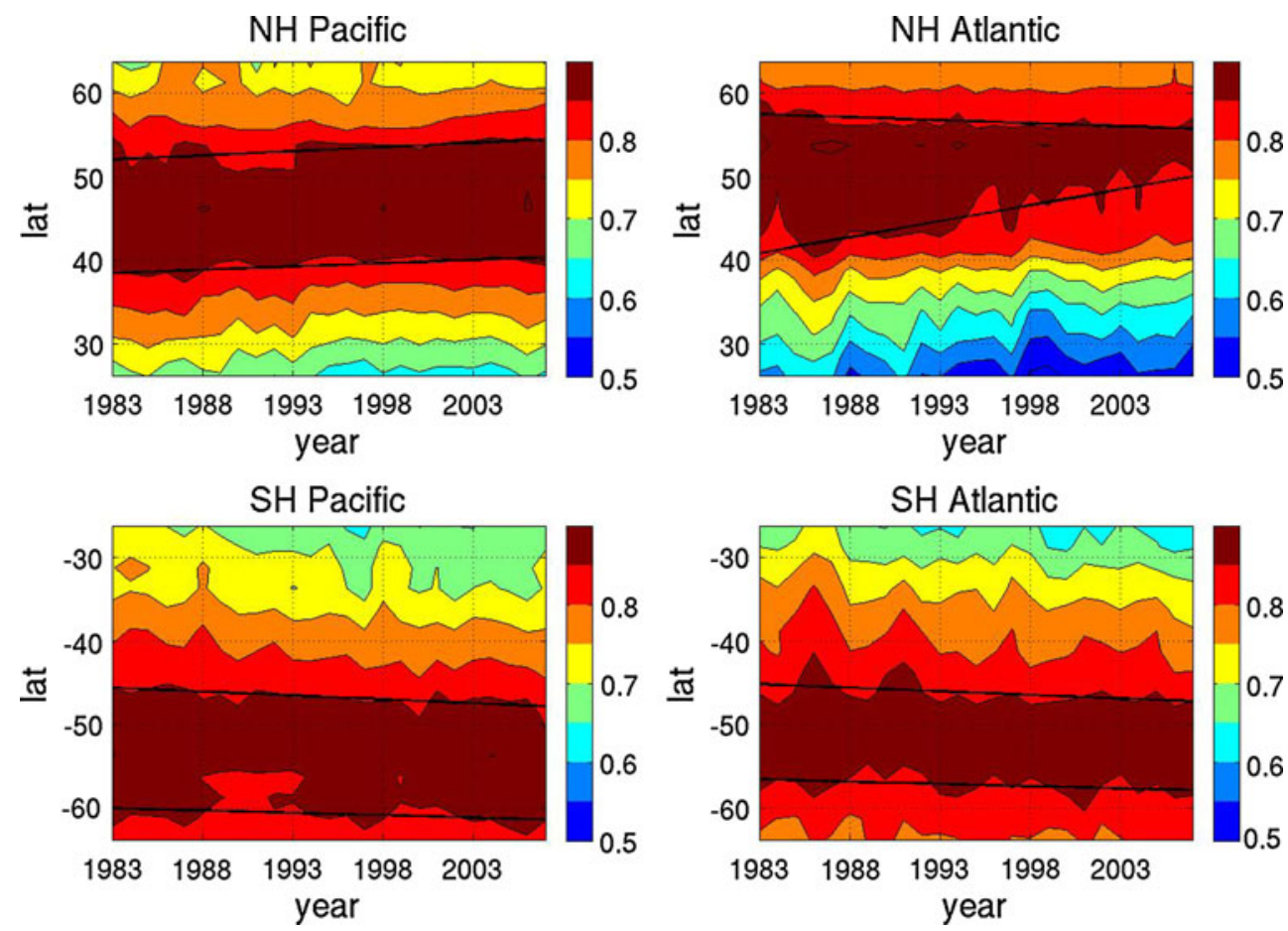

western part of the NH Pacific should be relatively free from bias, and in Sect. 3.1 this area is used as a reference region. The similarity between trends in this region and in the whole NH Pacific and the two $\mathrm{SH}$ regions gives confidence to the results for those regions.

Generally, if the regions at the limbs of the stationary satellite footprints were causing spurious changes in the storm track cloudiness, our results would change upon exclusion of the identified trouble areas, but a comparison of the ISCCP analysis including and not including the seams between GMS/GOES in the $\mathrm{NH}$ and $\mathrm{SH}$ Pacific, centered around $200^{\circ} \mathrm{E}$, and GOES/METEOSAT in the SH Atlantic, centered around $300^{\circ} \mathrm{E}$ respectively, does not reveal such differences, suggesting that our results for these three regions are adequately free from this artificial influence.

This can also be illustrated by looking at narrower zonal slices of the storm track regions over each of the three remaining ocean basins, away from the problematic satellite seams. Such regions are found to show changes in cloudiness similar to those for the whole storm track regions (see Sect. 3.1).

\subsubsection{Regression of VZA dependence}

An approach taken by Clement et al. (2009) to account for the spurious VZA-related variability in cloud cover is to "regress out" the VZA-related variability in cloud cover. Applied to the global ocean total mean cloud cover, we find that this reduces the (linear fit) trend from $-1.5 \%$ per decade to $-0.4 \%$ per decade over the ISCCP period. For the regional mean cloud cover in the storm track regions, the correction is smaller, as further discussed in Sect. 3.1.

The correlation between VZA and cloud fraction decreases from global mean to regional mean scale and even more, when taken to a grid box level. Applying this kind of correction therefore forces a linear dependence on a relation that is not truly linear (particularly if done grid box by grid box). Furthermore, the correlation between VZA and cloud fraction does not necessarily imply causality and it is possible that the correction itself is unphysical.

There may also be artificial trends in the ISCCP data due to drift and calibration problems of single geostationary satellites, affecting the global temporal pattern [Norris (2000), Knapp (2007)]. Individual satellite trends can be regressed out of the total timeseries (as done by Clement et al. (2009)), but thereby real physical trends are lost as well, which precludes any trend analysis. Repeated ISCCP analysis over areas restricted to either side of the seams of the respective geostationary satellite footprints indicates similarity, rather than different trend patterns due to individual satellite drift. The focus regions of the present study are also covered by different geostationary satellites (GMS and GOES over the Pacific, METEOSAT and GOES over the Atlantic), and it is unlikely that these individual satellites are all afflicted by equivalent spurious trends, dominating the cloudiness patterns and time series for the different regions in similar ways. Also, as cloud fraction is determined from tests of inhomogeneity of the radiance field seen by the satellite, there is not physical reason for it 
to be significantly affected by drift or calibration issues, except possibly for thin clouds, as further discussed below.

\subsubsection{Selective cloud type analysis}

The problems associated with VZA-dependence, as well as calibration errors and drift are primarily concerns for thin clouds, as they may fall above or below detection thresholds depending on viewing angle or calibration. The correlation between VZA and cloud fraction is significantly reduced upon exclusion of the three most optically thin ISCCP cloud categories (referred to as cumulus, altocumulus and cirrus) from the total cloud fraction. A third possible way to account for the artificial variability is therefore to focus only on thicker cloud types, that we do not have the same physical reason for distrusting. This exclusion of certain cloud types is precarious not only because it may eliminate real variability. It may also introduce new artificial variability due to compensation between different cloud types. For instance, an increase in optically thick deep convective cloud associated with a decrease in thinner cirrus or cirrostratus cloud in the same altitude class, is more likely an indication of a classification shift than a physical change. Effects of this kind, as well as the from-above perspective of the satellite (meaning that only clouds not obscured by higher level clouds contribute to the cloud fractions in lower levels) also serve as general justification for the use of the composite quantity total cloud fraction in the present analysis, rather than individual cloud types. But the use of total cloud fraction, as well as spatial and temporal averaging, inevitably results in aggregation of the actual cyclone patterns in individual cloud types, demonstrated by e.g. Field and Wood (2007) and Field et al. (2008).

\section{Results}

\subsection{Changes in cloudiness and radiative fluxes}

\subsubsection{ISCCP, with selective regional analysis}

In ISCCP observations of total cloud fraction, the four regions studied display distinct maxima in zonal mean cloud cover, with annual averages reaching up to over $90 \%$ fractional cloud cover. See Fig. 1. Although not the only source of cloud variability in the domains studied, the cyclone activity can be assumed to be the dominant contributor to these maxima, that we use to represent the storm tracks. The observations also indicate a slight poleward shift of the maxima over the 25 years of available data, as seen from the poleward slant of the total cloud fraction contour lines in Fig. 1. The shift is more pronounced at the equatorward side, resulting in a narrowing of the storm track extent. Similar patterns are found over all of the four ocean basins $\mathrm{NH}$ and SH Pacific and $\mathrm{NH}$ and SH Atlantic (latitudes $25^{\circ}-65^{\circ} \mathrm{N}$ and $65^{\circ}-25^{\circ} \mathrm{S}$ respectively and longitudes $120^{\circ}-240^{\circ} \mathrm{E}$ and $280^{\circ}-360^{\circ} \mathrm{E}$ respectively). The $\mathrm{NH}$ Atlantic shows a much stronger narrowing than the other regions (also evident from Table 1), which may be an indication that the data from this region are indeed problematic as inferred from Evan et al. (2007) (see Sect. 2.1). Expanding the NH Atlantic domian poleward to include more of the cyclone activity in this ocean basin suggests more of a an actual shift in this region as well. The $\mathrm{NH}$ Atlantic storm track variability is also related to the NAO, and postive NOA phase is associated with a northward shift of the storm track. NAO indices have indeed been positive during most of the studied period [Hurrell and Deser (2010)] [e.g.], but a consistent increase in NAO index corresponding to a consistent poleward shift is not evident.

The actual storm track intensity varies with season, in a way that may change with global warming (see e.g. O'Gorman (2010)). The patterns of poleward shift that we focus on here appear to be similar across seasons, and the results presented in the following are for annual means. (For ISCCP data, annual means are taken from July to June, whereas for other data sets they are taken from January to December. In cases of one or more missing months the whole year is treated as missing).

To quantify a shift in position of the storm track cloudiness we define the central latitude of total cloud cover $\left(\varphi_{c}\right)$ in each storm track region. This follows Tsushima et al. (2006), who study the poleward shift of the center of cloud water distribution in CGM simulations with an analogous measure. Hereby,

$\varphi_{c}=\frac{\Sigma \varphi \cdot \overline{c l t}(\varphi)}{\Sigma \overline{c l t}(\varphi)}$,

where $\overline{c l t}(\varphi)$ is the zonally averaged total cloud fraction in each region, at latitude $\varphi$.

The ISCCP data indicate poleward shifts in $\varphi_{c}$ of between 0.15 and 0.17 degrees per decade (95\% significant) for the NH Pacific, SH Pacific and SH Atlantic, resulting in a shift of ca 0.4 degrees for the whole 25 year period in these regions. The $\mathrm{NH}$ Atlantic shows a larger shift, ca 0.6 degrees over 25 years, which is again believed to be partly spurious. These estimates are large compared to the GCM-estimated values of shift in central latitude of cloud water in the SH of Tsushima et al. (2006) (between 1 and 3.5 degrees from control to doubled $\mathrm{CO}_{2}$ climate), but significantly smaller than that given by Wang et al. (2006) for the winter $\mathrm{NH}$ Atlantic stormtrack from reanalysed sea level pressure data $\left(181 \mathrm{~km}\right.$ or $1.6^{\circ}$ shift in mean position from 1958-1977 to 1982-2001). The latter is however based on a completely different measure. 
Fig. 2 Regionally averaged ISCCP total cloud fraction annual means 1983-2008 for the four storm track regions $\mathrm{NH}$ Pacific (solid line), NH Atlantic (dashed line), SH Pacific (dotted line) and SH Atlantic (dashdotted line). The red solid line shows the western NH Pacific regional average. We place less confidence in the NH Atlantic trends, for the reasons discussed in Sect. 2.1

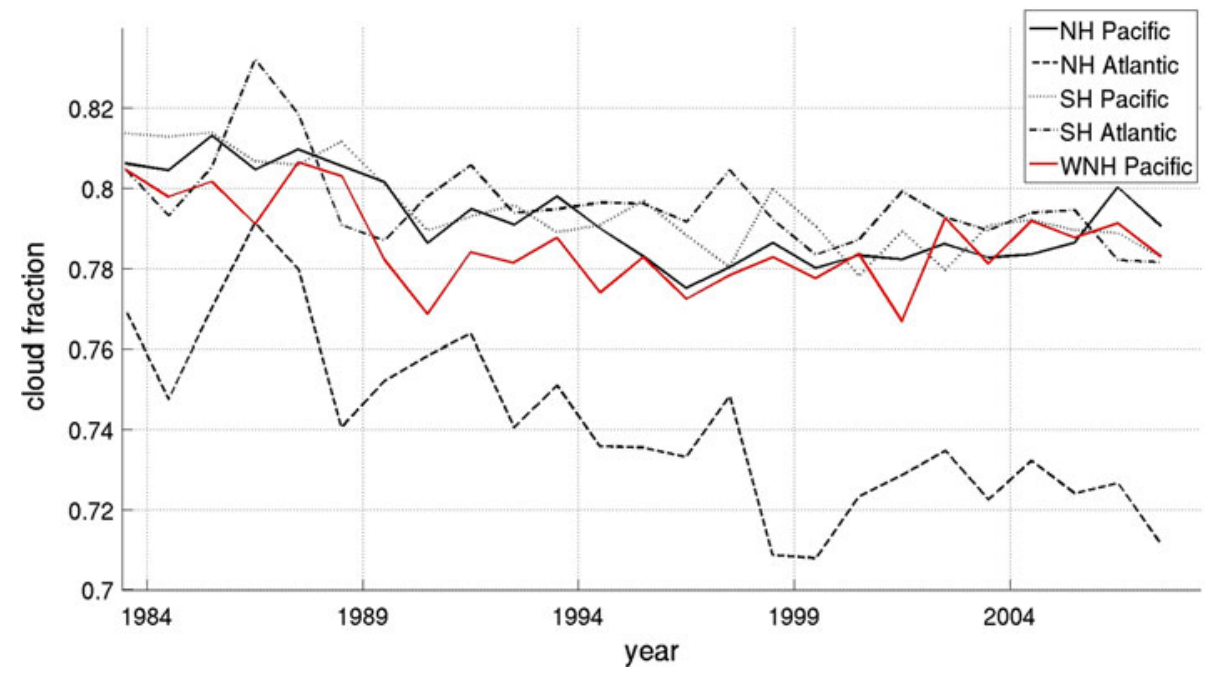

Table 1 Shift and narrowing of storm tracks quantified in various ways, from deseasonalized ocean-only monthly mean ISCCP data July 1983 to June 2008, for each of the four storm track regions

\begin{tabular}{|c|c|c|c|c|c|}
\hline & NH Pacific & WNH Pacific & NH Atlantic & SH Pacific & SH Atlantic \\
\hline clt reduction & 0.88 & 0.47 & $(2.20)$ & 1.10 & 0.89 \\
\hline Poleward $\varphi_{c}$ shift & 0.15 & 0.09 & $(0.24)$ & 0.16 & 0.17 \\
\hline Poleward clt 85 shift (p) & 1.00 & 0.95 & $(-0.72)$ & 0.55 & 0.54 \\
\hline Poleward clt 85 shift (e) & 0.78 & 0.48 & (3.82) & 0.93 & 0.86 \\
\hline
\end{tabular}

Values for the western $\mathrm{NH}(\mathrm{WNH})$ Pacific are shown for reference. clt reduction denotes the magnitude of the linear fit negative trend in total cloud cover [\% per decade], poleward $\varphi_{c}$ shift is the magnitude of the linear fit poleward trend in central latitude as given by Eq. 1 [degrees per decade], poleward clt $_{85}$ shift (p) and poleward clt $_{85}$ shift $(e)$ are the magnitudes of the linear fit poleward trend in position of the $85 \%$ cloud cover isoline [degrees per decade] on the poleward and equatorward sides of the cloud fraction maximum respectively. Trends whose $95 \%$ confidence intervals exclude 0 are in bold. The italicized values indicate $85 \%$ significance. We place less confidence in the values for the NH Atlantic (given in brackets), as discussed in Sect. 2.1

Another way of quantifying the changes in storm track position is using the change in location of a certain isoline for cloud fraction. Linear fits to the latitudinal boundaries for the band of total cloud fraction larger than for instance $85 \%$ ( $\operatorname{clt}_{85}$ ), as shown in Table 1, indicate shifts of up to several degrees over the 25 -year period. Similar results hold for different choices of cloud fraction limits; for all regions except the $\mathrm{NH}$ Atlantic, the poleward and the equatorward boundaries both show a poleward trend, indicating an actual shift, rather than just a narrowing. The magnitudes of the clt $_{85}$ trends at the poleward sides are, with the exception of the NH Pacific, smaller than those at the equatorward sides, and have weaker statistical significance. The position of the poleward cloud fraction boundary isoline in the SH Pacific is particularly difficult to assign statistical significance, due to the temporary narrowing of the highest cloud fraction area in the early 1990's. Longer data series would of course be helpful in determining the robustness of the trends.

The shift and narrowing of the storm track bands are accompanied by decreases in regional mean total cloud cover in the same areas, as seen in Fig. 2. Fitting a linear trend to each area-averaged total cloud fraction indicates decreases in fractional cloud cover around $2 \%$ in the storm track regions of the $\mathrm{NH}$ and SH Pacific and SH Atlantic, over the 25-year long ISCCP record (between 0.9 and 1.1 $\%$ per decade, as given in Table 1). These trends are also 95\% significant. Here the North Atlantic region again stands out, showing a much larger decrease in total cloud fraction (2.2\% per decade), which is likely in part artificial. The other regions, where the data are considered more trustworthy, cluster together, and show similar trends, which gives confidence to those data.

As further confirmation, Fig. 2 also shows the trend in the western part of the NH Pacific (latitudes $25^{\circ}-65^{\circ} \mathrm{N}$ and longitudes $120^{\circ}-180^{\circ} \mathrm{E}$ ). As seen from Table 1, the magnitudes of the shift and narrowing of the storm track cloudiness in the west NH Pacific are smaller than for the full storm track region. This may be an indication of exaggeration in the unadjusted total $\mathrm{NH}$ Pacific data, but spatial inhomogeneity within the domain may also be an issue. As previously mentioned, the cloud variability in the focus regions is not only cyclone-related, and differences in other weather systems and local cloud-forming processes 
may lead to area-dependent differences. For instance, the cloud maximum due to the stratocumulus deck off the coast of California, partly included in the total NH Pacific domain, is completely excluded in the WNH Pacific region. Still, the general similarity between the western and the total Pacific, and the other storm track regions, increases the credibility of the trend patterns in those regions.

Smaller regions within each storm track region, excluding potential areas of spurious variability, also serve as support for the above results. For instance the regions between $150^{\circ} \mathrm{E}$ and $170^{\circ} \mathrm{E}$ in the NH Pacific and SH Pacific and between $320^{\circ} \mathrm{E}$ and $340^{\circ} \mathrm{E}$ in the SH Atlantic, show decreases in cloud cover similar to those given in Table 1 for the whole storm track regions (NH Pacific 0.7, $\mathrm{SH}$ Pacific 1.3 and SH Atlantic $1.1 \%$ per decade). The poleward shift in central latitude for cloudiness $\varphi_{c}$ is also comparable to, although somewhat smaller than, the values in Table 1 for the NH Pacific, SH Pacific and SH Atlantic, $(0.12,0.15$ and 0.14 degrees per decade respectively in these sub-regions). Similar results hold for other choices of limited regions within each satellite footprint.

The main part of the decease in total cloud fraction can be ascribed to decreases in what ISCCP classifies as low clouds. High and middle level cloud fraction rather tend to increase in the study areas, as seen in Fig. 3. When segregated by cloud top height the NH Atlantic cloud fraction shows a general similarity with the other storm track regions, and the western NH Pacific cloud fraction again follows that of the full $\mathrm{NH}$ Pacific region.

\subsubsection{ISCCP, with regression of VZA dependence}

Following Clement et al. (2009) we apply an adjustment to the cloud fraction time series by performing a linear
Table 2 Same as Table 1, but for VZA-adjusted ISCCP data

\begin{tabular}{lllll}
\hline & NH & NH & SH & SH \\
& Pacific & Atlantic & Pacific & Atlantic \\
\hline clt reduction & $\mathbf{0 . 6 9}$ & $\mathbf{1 . 6 4}$ & $\mathbf{1 . 0 3}$ & $\mathbf{0 . 4 8}$ \\
Poleward $\varphi_{c}$ shift & $\mathbf{0 . 0 9}$ & $\mathbf{0 . 1 7}$ & $\mathbf{0 . 1 4}$ & $\mathbf{0 . 1 1}$ \\
Poleward clt $_{85}$ shift $(\mathrm{p})$ & $\mathbf{0 . 6 4}$ & $\mathbf{0 . 4 6}$ & 0.11 & 0.34 \\
Poleward clt $_{85}$ shift $(\mathrm{e})$ & $\mathbf{0 . 6 0}$ & $\mathbf{2 . 8 0}$ & 0.46 & 0.28 \\
\hline
\end{tabular}

Trends whose $95 \%$ confidence intervals exclude 0 are in bold. The italicized values indicate $85 \%$ significance

regression of regional mean cloud fraction on the regional mean value of $\mu(1 / \cos (V Z A))$, and subtracting the alleged VZA-induced variability from the cloud fraction time series, for each of the storm track regions. The resulting cloud fraction time series show smaller negative trends and weaker poleward shifts, as seen in Table 2 .

As expected, the thinner clouds are more affected by this VZA-related adjustment. The decrease in total and low cloud fraction, and increase in middle and high cloud fraction, as in the selected regional data, remains in the VZA-adjusted data.

\subsubsection{ISCCP, with selective cloud type analysis}

As discussed in Sect. 2.1, the thin clouds are reasonably the ones most affected by artificial variability. Combining cloud types by thickness, rather than by altitude level, we find that the decrease in total cloud is actually primarily due to these most optically thin clouds. The thicker clouds (medium+thick) decrease in the NH Atlantic, but remain more constant, or even increase in the other storm track
Fig. 3 ISCCP annual mean low (dash-dotted line), middle (dashed line) and high (solid line) cloud fraction for the four storm track regions NH Pacific (upper left), NH Atlantic (upper right), SH Pacific (lower left) and SH Atlantic (lower right) 1983-2008. The red lines in the upper left panel represent the western NH Pacific
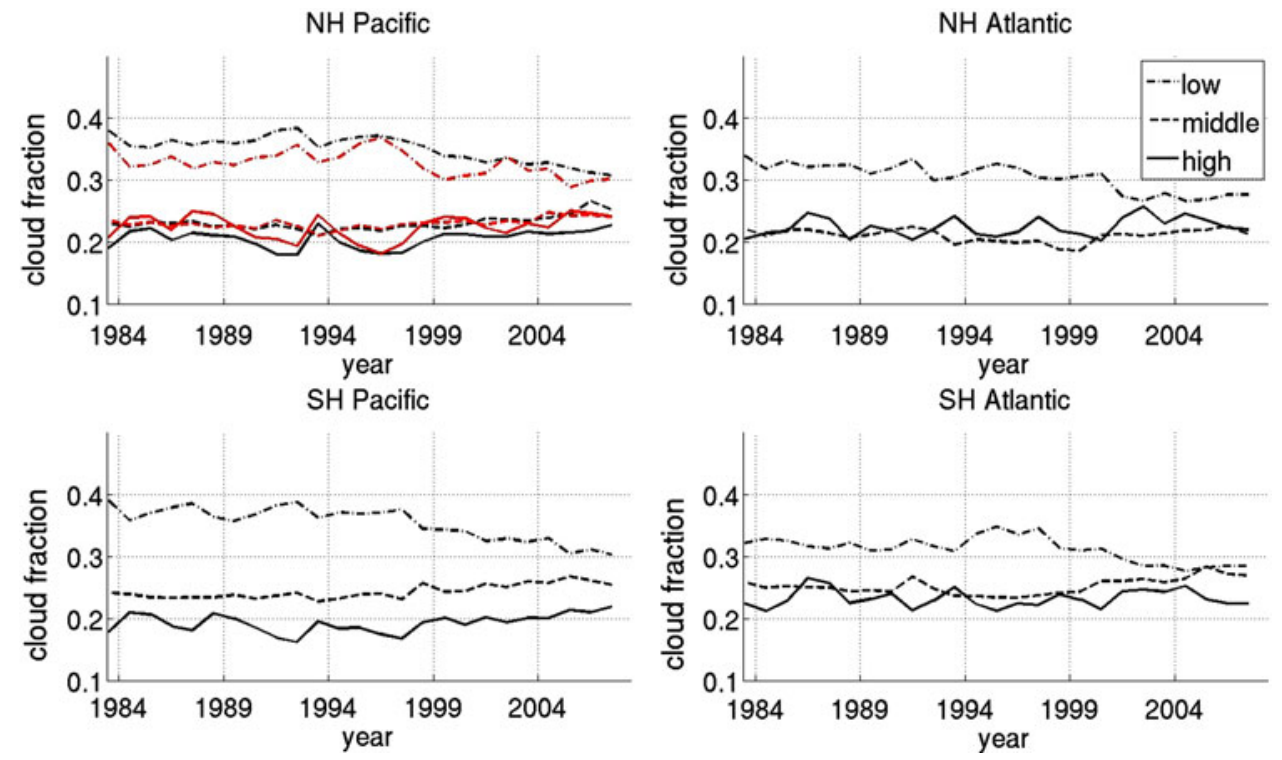
Fig. 4 ISCCP annual mean thin (solid line) and thicker (medium + thick) (dashed line) cloud fractions, corresponding to clouds with optical thickness below and above 3.6 respectively, for the four storm track regions NH Pacific (upper left), NH Atlantic (upper right), SH Pacific (lower left) and SH Atlantic (lower right) 1983-2008
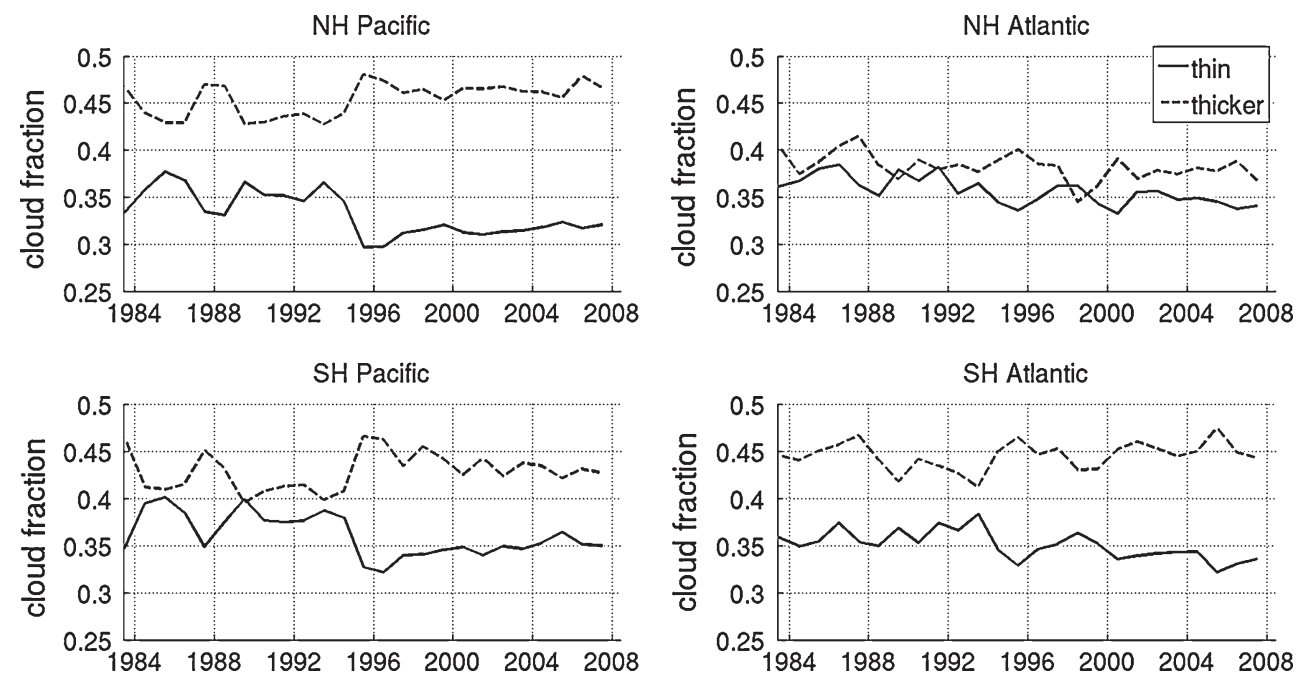

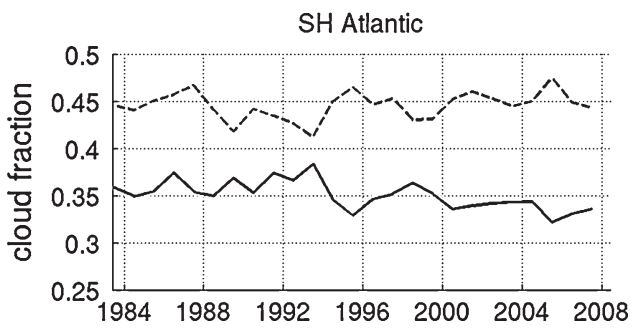

regions, as seen in Fig. 4. Excluding the three (low, middle and high) thinnest cloud categories and computing total cloud fraction from the remaining cloud categories significantly reduces and in some cases even reverses the negative trend and the poleward shift, as seen in Table 3. However, the anti-correlation between thin and thicker clouds apparent in Fig. 4 illustrates the difficulty of removing a cloud category in this way, as discussed in Sect. 2.1.

Moreover, the shift measures of Table 1 are not quite appropriate here, and might be misleading, as there are missing data at latitudes poleward of $55^{\circ}$, partly excluding the cloud maxima of the storm tracks.

Yet, when excluding the thin clouds the picture of Fig. 3 still remains; low clouds decrease whereas middle and high level clouds increase.

Table 4 summarizes the changes in total cloud fraction and upper (high + middle) cloud fraction, using unadjusted ISCCP data for selected regions, data adjusted for VZA-dependence and data excluding thin clouds.

Table 3 Same as Table 1, but for ISCCP data excluding optically thin clouds (with optical thickness below 3.6)

\begin{tabular}{lllll}
\hline & NH & NH & SH & \multicolumn{1}{l}{ SH } \\
& Pacific & Atlantic & Pacific & Atlantic \\
\hline clt reduction & $\mathbf{- 1 . 3 7}$ & $\mathbf{0 . 7 6}$ & -0.42 & -0.05 \\
Poleward $\varphi_{c}$ Shift & $\mathbf{0 . 1 4}$ & 0.01 & $\mathbf{0 . 0 3}$ & $\mathbf{- 0 . 1 3}$ \\
Poleward clt 45 shift (e) & -0.47 & $\mathbf{0 . 6 6}$ & 0.44 & 0.01 \\
\hline
\end{tabular}

Trends whose $95 \%$ confidence intervals exclude 0 are in bold. Note that poleward $\mathrm{clt}_{85}$ shift $(e)$ is replaced by poleward $\operatorname{clt}_{45}$ shift $(e)$ and that poleward clt $_{45}$ shift $(e)$ is not included, as a consequence of data coverage only within $55^{\circ} \mathrm{S}$ and $55^{\circ} \mathrm{N}$
Table 4 Linear fit trend in total and upper (high + middle) cloud fraction for original ISCCP data, VZA-adjusted data and data with thin clouds excluded [\% per decade]

\begin{tabular}{|c|c|c|c|c|}
\hline & NH Pacific & NH Atlantic & SH Pacific & SH Atlantic \\
\hline \multicolumn{5}{|c|}{ Unadjusted } \\
\hline Total & -0.9 & $(-2.2)$ & -1.1 & -0.9 \\
\hline Upper & 1.5 & $(0.5)$ & 1.9 & 0.9 \\
\hline \multicolumn{5}{|c|}{ VZA-adjusted } \\
\hline Total & -0.7 & -1.6 & -1.0 & -0.5 \\
\hline Upper & 0.8 & 0.8 & 1.2 & 1.2 \\
\hline \multicolumn{5}{|l|}{ No thin } \\
\hline Total & 1.3 & -0.7 & 0.5 & 0.3 \\
\hline Upper & 1.9 & 0.3 & 1.7 & 1.2 \\
\hline
\end{tabular}

Trends whose $95 \%$ confidence intervals exclude 0 are in bold. The italicized values indicate $85 \%$ significance

\subsubsection{Additional cloud and radiation data sets}

The decrease in cloud cover on a global mean scale seen in the ISCCP data (see "Appendix", Fig. 9), is, as discussed in Sect. 2.1, believed to be at least partly spurious, and we refrain from laying emphasis on it.

We note however that changes in top-of-the-atmosphere (TOA) radiation estimates from ERBE are consistent with a global mean decrease in cloud cover, showing a decrease in reflected near-global shortwave (SW) radiation and an increase in outgoing near-global longwave (LW) radiation during the part of the ISCCP period they cover (see "Appendix", Fig. 10). Model reconstructions of radiative fluxes based on the ISCCP cloud product (ISCCP FD) also show close agreement with ERBE fluxes over the tropics, in variability as well as in trend [Zhang et al. (2004)].

Large interannual variability, particularly that related to the eruption of Mount Pinatubo in 1991, as well as instances of missing data, in the mid- and late 1990's, make 
evaluation of trends from these time series difficult. For the four storm track regions, tentative trends are even more obscured by interannual variability, but in accordance with the total cloud cover changes, all four areas suggest a weak decrease in reflected SW flux, and the NH Pacific, SH Pacific and NH Atlantic also show an increase in outgoing LW flux. In the SH Atlantic the LW trend is weakly negative. As further pointed out in Sect. 3.2, particularly in the LW, the total cloud fraction is not the only determinant of the radiative flux changes.

Extending the cloud cover data with observations from MODIS for the period 2001 to 2009 does not significantly change the picture. The changes in the MODIS record are subtle in all regions, but the time period covered is also very short. The central latitudes of cloud cover, as measured by Eq. 1 do not show statistically significant shifts. The area-averaged changes in total cloud fraction are in accordance small, but slightly negative for all regions but the NH Pacific (as is also suggested by ISCCP, indicating a slight rebound in the cloud cover decrease at the end of the record). A decreasing trend can be seen in liquid cloud fraction, whereas ice cloud fraction, shows a slightly increasing trend in all regions except the NH Atlantic. The cloud water path also decreases in all regions.

The ISCCP and MODIS records are not identical during the time of overlap, reflecting the effect of different satellites, instruments and retrieval algorithms on the cloud fraction estimates. Similarly CERES flux estimates, coincident with MODIS, are not directly comparable with the preceding ERBE data. However, CERES ES4 global radiative fluxes, in agreement with MODIS cloud data, show small negative reflected SW flux changes for all regions but the NH Pacific. The outgoing LW flux weakly decreases in all regions. Again, we consider the CERES and MODIS records to be too short for trend analysis, but we also note that weaker storm track changes seen in these data sets are consistent with the levelling temperature increase during the time period they cover, and/or with the trends in the ISCCP data being artificially exaggerated.

\subsection{Implications for radiative forcing and cloud feedback}

The cloud radiative forcing (CRF), i.e. the difference between the clear-sky and the all-sky TOA radiative fluxes associated with the storm tracks may be estimated from ERBE and CERES, for SW, LW and net radiation, for the limited time for which both clear-sky and all-sky flux estimates are available. ERBE S4G (available for five full years, 1985-1989) and CERES (available for 7 full years, 2001-2005 and 2007-2009) both show negative (cooling) SW CRF and positive (warming) LW CRF in the storm track regions, the $\mathrm{SW}$ dominating, leading to a net negative (cooling) effect of clouds over the four regions studied, ranging from $-38 \mathrm{~W} \mathrm{~m}^{-2}$ to $-24 \mathrm{~W} \mathrm{~m}^{-2}$. The seasonal cycle is pronounced, particularly in the SW, and counteracts the local seasonal temperature variation, with peak net cooling in local summer and vice versa, for all four regions, as pointed out for the NH Pacific and Atlantic by Weaver and Ramanathan (1997).

The lengths of the available independent observational records of CRF are insufficient for any trend analysis, but the relation between clouds and radiation can give an idea of magnitudes of cloud-induced changes in radiative fluxes.

The variability in SW and LW CRF is very well correlated with the variability in the respective radiative total sky fluxes, with regression coefficients approximately equal to 1 , and the latter can satisfactorily be used to represent the cloud-induced alterations to the radiative budget (See "Appendix", Table 5). The correlations between SW and SW CRF are generally higher than those between LW and LW CRF, which reflects that not only clouds, but also other properties like water vapour content and temperature are important for determining the outgoing LW radiation (see also Norris (2005)). The correlations based on CERES ES4 are higher than those based on ERBE S4G.

Further, with sufficient correlation between cloud cover and radiative fluxes the full ISCCP cloud record may be used to coarsely estimate the changes in radiative fluxes. This can give a more consistent estimate than the broken record of combined ERBE and CERES observations.

In the SW, to first order, the variability in radiative flux is closely related to variability in total cloud cover, through the cloud albedo. For instance, Loeb et al. (2007) show very close co-variability between global mean CERES SSF SW flux and MODIS total cloud fraction. We find similar relations in several combinations of satellite data sets. In more limited areas, like the storm track regions studied here, the correlations are generally higher than for the global ocean mean (See "Appendix", Table 6).

In the LW the correlations with total cloud fraction in the storm track regions are negative, generally significant, but weak for different combinations of data sets (See "Appendix", Table 6). Since LW and LW CRF are well correlated ("Appendix", Table 5), this indicates the importance of other cloud properties than total cloud fraction for driving the LW variability. MODIS ice cloud fraction for instance, is very well correlated with CERES LW flux. For the longer ISCCP record, the use of upper cloud (i.e. the sum of ISCCP classified high and middle clouds, following Norris (2005)) increases the magnitude of the negative correlations.

Linear regression indicates that a $1 \%$ anomaly in total cloud fraction corresponds to an anomaly in reflected SW radiation at TOA of ca. $1 \mathrm{~W} \mathrm{~m}^{-2}$ (the $95 \%$ confidence intervals for regression coefficients in individual regions, 
and data set combinations, range from 0.6 to $1.9 \mathrm{~W} \mathrm{~m}^{-2}$ indicating the uncertainty in this estimate), and that a $1 \%$ anomaly in upper cloud fraction corresponds to an anomaly in outgoing $\mathrm{LW}$ radiation of ca. $-0.5 \mathrm{~W} \mathrm{~m}^{-2}$ (similarly, the $95 \%$ confidence interval range is from -1 to $-0.2 \mathrm{~W} \mathrm{~m}^{-2}$ ) (See "Appendix", Table A2).

Based on these relations, we crudely estimate the effect of the changes in cloudiness seen in the ISCCP record.

From Table 4, the decrease in total cloud fraction during the 25 year ISCCP period is between 2 and $3 \%$ for the three storm track regions NH Pacific, SH Pacific and SH Atlantic. (Using the original ISCCP data we leave out the $\mathrm{NH}$ Atlantic region, as those data are considered less trustworthy.) This corresponds to decreases in reflected SW flux of ca $3 \mathrm{~W} \mathrm{~m}^{-2}$ in those three regions. Whereas the total cloud fraction decreases, the upper (high+middle) cloud fraction shows an increase (see Fig. 3 and Table 4), of between 2 and 5\%, which corresponds to decreases in outgoing LW flux between 1 and $3 \mathrm{~W} \mathrm{~m}^{-2}$, also regionwise.

Hence, the SW and LW effects both result in a warming. The estimated net radiative effect is between 3 and $5 \mathrm{~W} \mathrm{~m}^{-2}$ (NH Pacific $4.1 \mathrm{~W} \mathrm{~m}^{-2}$, SH Pacific $5.1 \mathrm{~W} \mathrm{~m}^{-2}$, SH Atlantic $3.4 \mathrm{~W} \mathrm{~m}^{-2}$ ), indicative of a positive cloud feedback of significant magnitude. This does not necessarily imply positive feedback on a global scale; we have not analyzed possible compensating negative feedbacks in other regions. For the NH Atlantic, the estimated net radiative effect of $6.1 \mathrm{~W} \mathrm{~m}^{-2}$ is most certainly exaggerated, but for the other regions as well, using the VZAadjusted trends leads to a downward adjustment, with net radiative effects between 3 and $5 \mathrm{~W} \mathrm{~m}^{-2}$ including all four regions (NH Pacific $2.8 \mathrm{~W} \mathrm{~m}^{-2}$, NH Atlantic $5.0 \mathrm{~W} \mathrm{~m}^{-2}$, SH Pacific $4.0 \mathrm{~W} \mathrm{~m}^{-2}$, SH Atlantic $2.8 \mathrm{~W} \mathrm{~m}^{-2}$ ). Using trends based on cloudiness with thin clouds excluded, the net effect is between 2 and $-1 \mathrm{~W} \mathrm{~m}^{-2}$ (NH Pacific $-0.9 \mathrm{~W} \mathrm{~m}^{-2}$, NH Atlantic $2.1 \mathrm{~W} \mathrm{~m}^{-2}$, SH Pacific $0.9 \mathrm{~W} \mathrm{~m}^{-2}$, SH Atlantic $0.8 \mathrm{~W} \mathrm{~m}^{-2}$ ).

This leads to a range of possible cloud radiative effect estimates, depending on how the data are treated. While the net radiative effect may be as large as $6 \mathrm{~W} \mathrm{~m}^{-2}$, it may also significantly smaller, or possibly even negative, as suggested by exclusion of thin clouds.

We also note that the inferred cloud-induced LW changes are negative, whereas the regional mean LW flux according to ERBE increases during the period of study. This is not an inconsistency, but merely indicates that had the (upper level) clouds not changed as they do the total LW increase would have been even larger.

\subsection{Comparison with CMIP3 models}

Among the CMIP3 models we find that several, albeit not all, demonstrate that the storm track shift previously documented in other atmospheric properties, is also manifested as a poleward shift in the midlatitude maximum of fractional cloud cover. The shift is most conspicuous in heavily forced model simulations, but even there, the changes are not consistent across models and also not consistent between the four regions studied.

Clement et al. (2009) study observed relations between clouds and several other meteorological quantities over the North East Pacific to construct a test of the ability of climate models to reproduce decadal scale low-level cloud feedback. The only CMIP3 model that passes this test and is considered trustworthy in future climate simulations, UKMO HadGEM1, suggests a positive cloud feedback over the Pacific in simulations with increased $\mathrm{CO}_{2}$ concentrations. This model is found here to be one of several models that simulate a poleward shift of the NH Pacific storm track cloudiness when forced by a $1 \%$ per year increase in $\mathrm{CO}_{2}$ concentration. It also shows a shift in the $\mathrm{SH}$ storm track cloudiness, but not in the NH Atlantic.

Out of 20 CMIP3 models, seven [BCCR-BCM2.0, CGCM3.1(T47), CNRM-CM3, CSIROMk3.0, MIROC3.2 (medres), MIROC3.S(hires) and MRI-CGCM2.3.2] show statistically significant $(95 \%)$ poleward shifts in storm track position, as measured by the central latitude of cloud fraction, Eq. 1, in all four regions studied. In the rest of the models, statistical significance cannot be assessed for the trend in at least one of the regions. Only two models, PCM and CCSM3, show equatorward trends in $\varphi_{c}$ with statistical significance, in the NH Pacific and the NH Atlantic respectively. Figure 5 summarizes these results for 20 CMIP3 models.

One of the CMIP3 models that most clearly shows a poleward shift in all four storm track regions is MIROC3.2 (medres), see Fig. 6. The magnitude of the shift in $\varphi_{c}$ is still around a factor of three smaller than the ISCCP observations show, despite the strong $\mathrm{CO}_{2}$ forcing in the simulation. This is consistent with the results of Johanson and Fu (2009), who find a discrepancy between models and observations of Hadley cell widening over the past decades (see also Sect. 3.5). But it may also be indicative of exaggeration in the ISCCP data. The discrepancy between models and observations is somewhat reduced when ISCCP data are linearly adjusted for VZA dependence. MIROC3.2 (like HadGEM1 and a majority of the CMIP3 models) also shows a decrease in total cloud fraction averaged over the Pacific, as well as globally, in response to increased $\mathrm{CO}_{2}$ forcing, consistent with positive cloud feedback. Out of the seven models showing poleward shifts in the storm tracks, only one (CGCM3.1(T47)) shows an increasing cloud fraction in response to increasing $\mathrm{CO}_{2}$.

It is also noteworthy that the poleward shift of the storm tracks is generally more pronounced in models with higher climate sensitivity. As seen from Fig. 5, none of the models 
Fig. 5 Slope of linear fit to position of central cloud cover latitude (as defined by Eq. 1) in the four storm track regions, in 20 CMIP3 models, over

80 years of simulation with $\mathrm{CO}_{2}$ concentration increasing by $1 \%$ per year. Values of slopes

whose $95 \%$ confidence intervals include 0 are marked with red.

Values of equilibrium climate sensitivity [K] for each model are given in brackets, with the exception of CNRM-CM3 and BCCR-BCM2.0, whose equilibrium climate sensitivities are not given by IPCC (2007)

Fig. 6 Hovmoller plots of total cloud fraction in the four storm track regions NH Pacific (upper left), NH Atlantic (upper right), SH Pacific (lower left) and SH Atlantic (lower right), in a simulation with MIROC3.2 (medres) with $\mathrm{CO}_{2}$ increasing by $1 \%$ per year to doubling, other forcings fixed at preindustrial levels
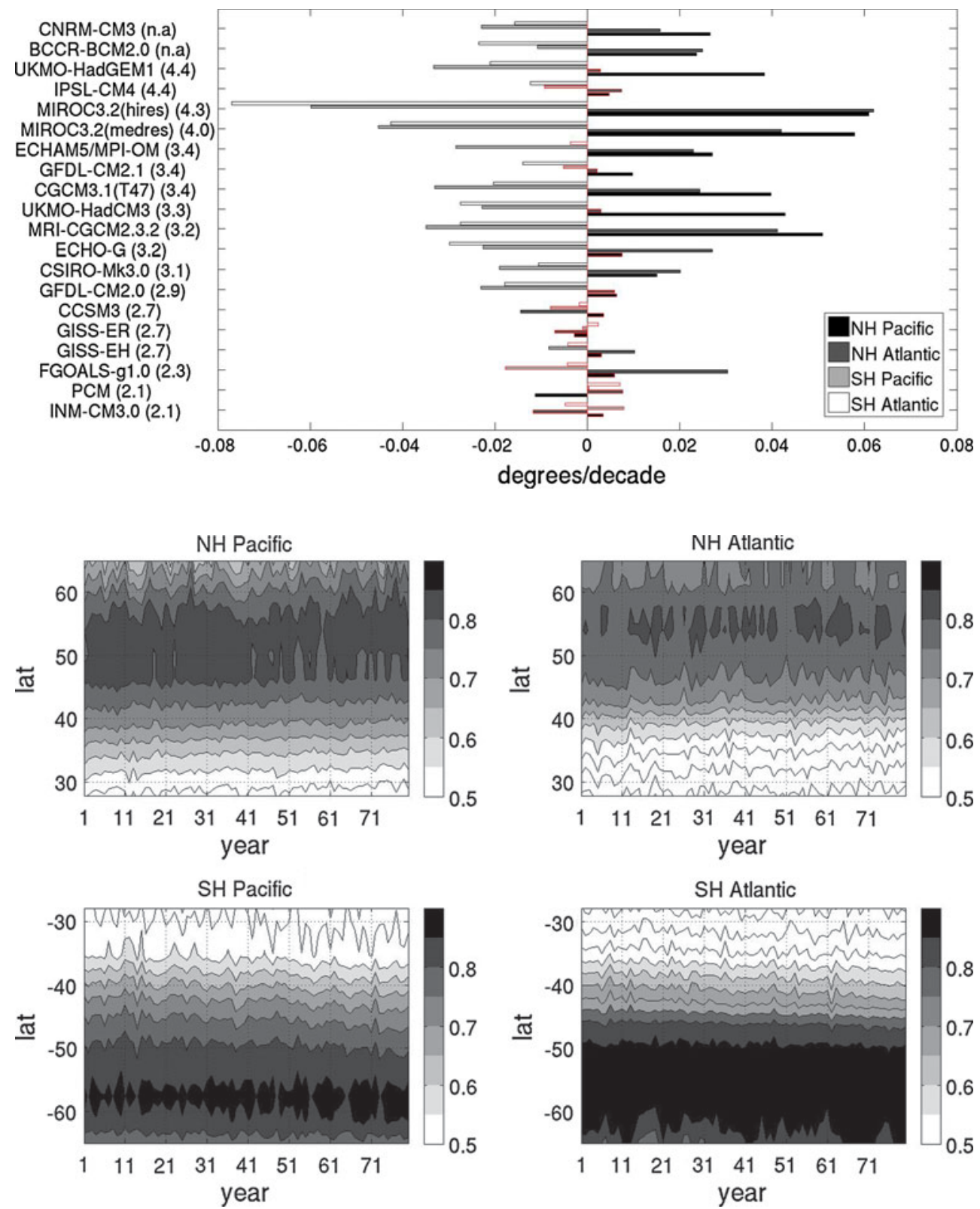

with documented equilibrium climate sensitivity lower than $3.0 \mathrm{~K}$ show a statistically significant poleward shift of the storm tracks in all four regions studied.

\subsection{Possible aerosol effects}

The uncertainty in the satellite data makes it difficult to assess possible aerosol effects on the storm track cloudiness changes. It is clear however that the four regions studied have quite different aerosol loadings. Estimates from MODIS show that monthly regional mean AOD in the $\mathrm{NH}$ and SH Atlantic and SH Pacific are below 0.2, whereas in the NH Pacific the mean AOD in contrast reaches above 0.6. See Fig. 7. The AOD in all regions show a seasonal variation, with generally higher AOD in the respective spring/summer months. The NH Pacific AOD is dominated by the springtime Asian dust plume [Zhu et al. (2007)], that can also be assumed to obscure outflow of other aerosol from Asia. There is indication that the Asian aerosol loading over the NH Pacific has varied, and increased on the whole, during the time period studied. Increases in emissions of anthropogenic $\mathrm{SO}_{2}$, black carbon (BC) and organic carbon (OC) from China and South East Asia are reported by Smith et al. (2001), Ohara et al. (2007), Bond et al. (2007) and Streets et al. (2008).

The fact that the storm track changes are broadly similar between hemispheres and ocean basins, despite the vastly different levels and distributions of AOD gives a first order indication that the changes in amount and location of clouds seen are not primarily due to aerosols. 
Fig. 7 Zonal and monthly distribution of MODIS AOD averaged between 2001 and 2009 , over four storm track regions, NH Pacific (upper left), $\mathrm{NH}$ Atlantic (upper right), SH Pacific (lower left) and SH Atlantic (lower right)

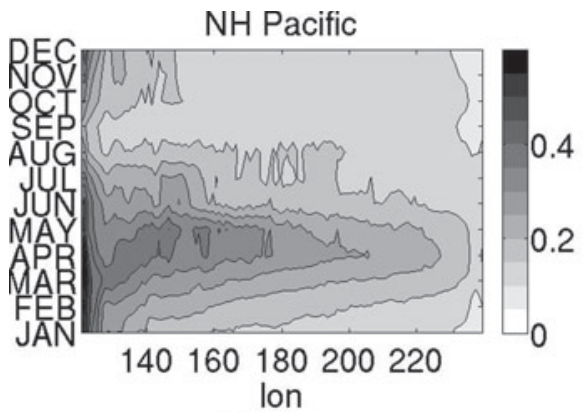

SH Pacific

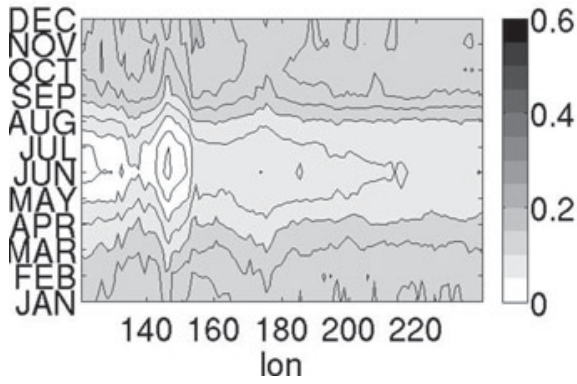

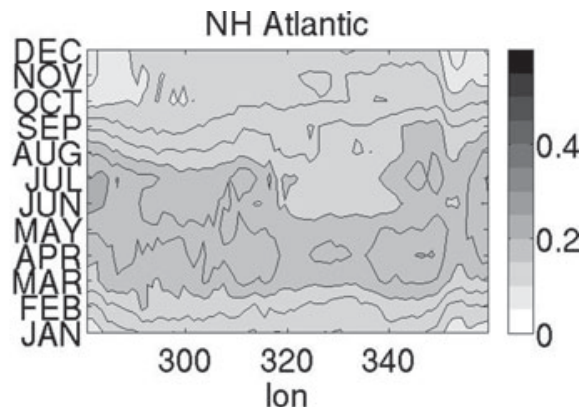

SH Atlantic

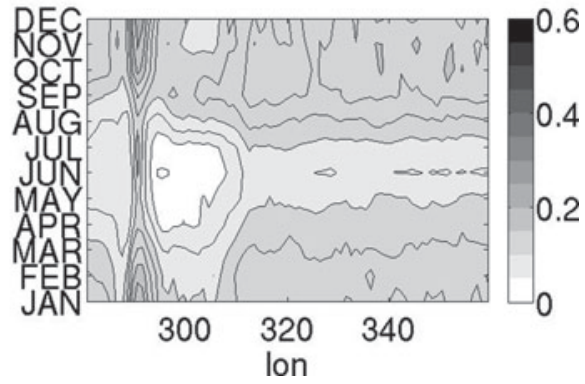

In the NH Pacific, there is also a sharp gradient in AOD, the climatological AOD decreasing with distance from the main source in Asia, implying asymmetry in possible indirect aerosol effects on cloudiness. If increases in aerosol due to the emission increases played a significant role for the cloud changes seen here, there should be interhemispheric differences between the western NH Pacific (where the climatological AOD distribution shows that the aerosol is primarily located) and the eastern NH Pacific (where there is less influence from Asian aerosol).
It has specifically been suggested [Zhang et al. (2007)] that Asian pollution has caused an intensification of the $\mathrm{NH}$ Pacific storm track, by increasing the deep convective cloud fraction, DCC. The DCC amount given by ISCCP increases over the NH Pacific, an increase that is not seen over the NH Atlantic or in the SH. As seen in Fig. 8, the trend is mainly due to a large increase in DCC in the mid 1990's, that occurs during fall and winter (September-February), when the DCC is maximum, but not in spring and summer, when the AOD is maximum. Wintertime Asian aerosol optical depth has indeed been found to increase during much of the period
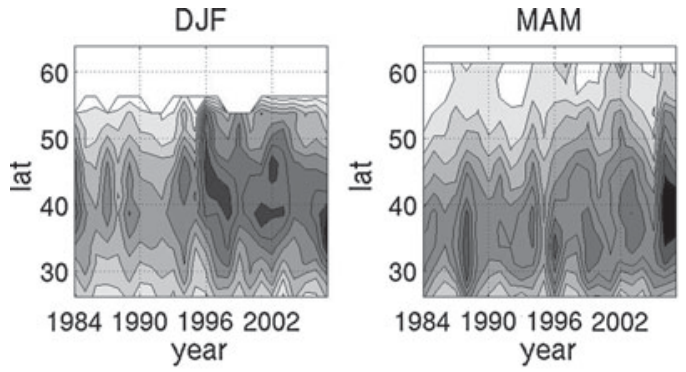

DJF
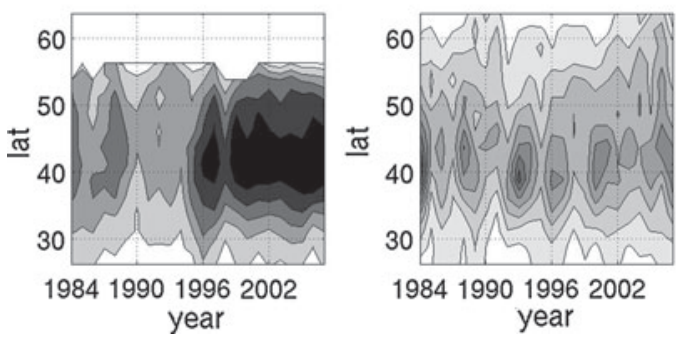

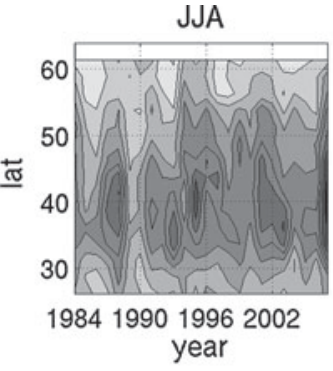

JJA

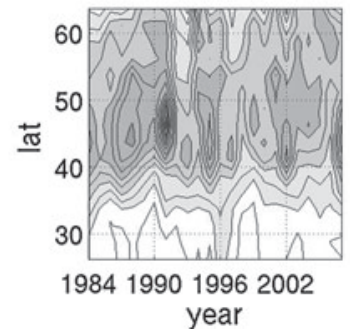

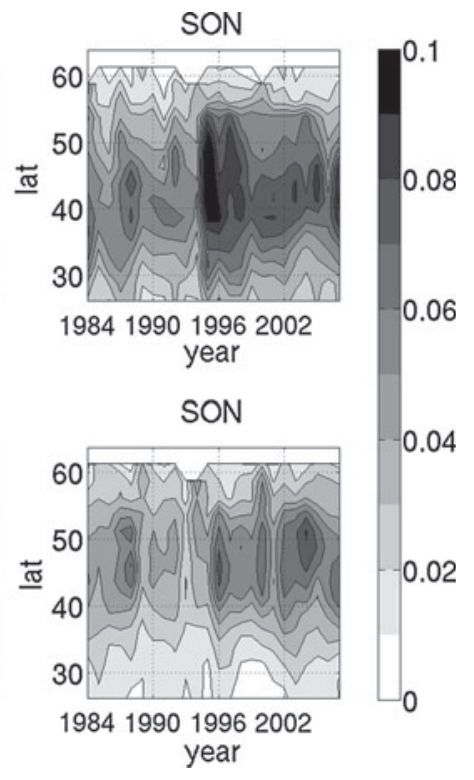

Fig. 8 Hovmoller plot of ISCCP deep convective cloud (DCC) fraction for the western NH Pacific storm track $\left(120^{\circ}-180^{\circ} \mathrm{E}\right)($ upper $)$ and eastern $\left(180^{\circ}-240^{\circ} \mathrm{E}\right)$ (lower) averaged over winter (DJF), spring (MAM), summer (JJA) and fall (SON) months 
covered by ISCCP [Massie et al. (2004)], but an abrupt change corresponding to the change in DCC is not evident. Trends in anthropogenic aerosol during spring, summer and fall are more difficult to assess due to the difficulty to separate dust from other aerosol. For sulfate aerosol, the emissions of the precursor $\mathrm{SO}_{2}$ are higher in winter [Smith et al. (2001)], whereas the photochemical production of sulfate is more effective in summer. Massie et al. (2004) attribute the increasing aerosol loading to increasing $\mathrm{SO}_{2}$ and other anthropogenic emissions. Assuming that such an increase in Asian aerosol loading occurs throughout the year, it should affect clouds not only in winter. Furthermore, the increase in DCC is at least as marked in the eastern part of the NH Pacific as in the western part (dividing the ocean basin at $180^{\circ} \mathrm{E}$ ), not reflecting the interhemispheric asymmetry of the aerosol loading.

It is also noteworthy that the regional mean increase in DCC in the mid-1990's coincides with a decrease in cirrus and cirrostratus, and that a general regional mean increase in thin and decrease in thicker (medium + thick) cloud is seen at the time (see Fig. 4), suggestive of a shift in cloud classification.

These arguments do not rule out an effect of Asian aerosol on DCC or other storm track clouds, but show that more detailed investigations with additional data sets are necessary to asses potential aerosol effects on the storm track cloudiness.

\subsection{Related changes in circulation}

The storm tracks result from baroclinic instability at the polar front, and changes in the meridional temperature gradient may be expected to be related to storm track changes. Following Fyfe (2003), we consider the meridional temperature gradient at $500 \mathrm{hPa}$. In analogy with the determination of the shift in central latitude of cloud cover in Sect. 3.1, we modify expression 1 to

$\varphi_{c T}=\frac{\Sigma \varphi \cdot \nabla \overline{T_{500}}(\varphi)}{\Sigma \nabla \overline{T_{500}}(\varphi)}$.

where $\nabla \overline{T_{500}}(\varphi)$ is the zonal mean meridional temperature gradient at $500 \mathrm{hPa}$ at latitude $\varphi$. Reanalysis data from the European Center for Medium-range Weather Forecast, ERA-40 [Uppala et al. (2005)], show statistically significant $(95 \%)$ shifts in the central latitude of the temperature gradient, $\varphi_{c T}$. The shift is to the north in the $\mathrm{NH}$ (by 0.2 degrees per decade) and to the south in the SH (by 0.4 degrees per decade), consistent with the poleward shifts in the storm track cloudiness. Similar trends are found for the central location of the meridional temperature gradient at 400 and $600 \mathrm{hPa}$.

We note consistency of our results with the previously documented expansion of the Hadley cell $[\mathrm{Hu}$ and $\mathrm{Fu}$
(2007), Lu et al. (2007)], that may be a consequence of global warming and stratospheric cooling as discussed by Johanson and Fu (2009). Such shifts in the Hadley circulation may affect the properties and structure of the low cloud field, and produce a signal in the statistics of the present analysis. With the subtropical subsidence zones reaching further poleward [Lu et al. (2007)], suppressed cloud formation in the subtropics may contribute to decreased cloud fraction in the regions studied here. But the changes seen are not likely merely a consequence of expanded Hadley circulation; in the selected regional, and VZA-adjusted data the total cloud fraction is found to display a shift, rather than only a narrowing, and the shift and narrowing are also seen in the latitudinal limits of the maximum cloud fraction band, located beyond tentative interference from the poleward leg of the Hadley circulation. Further, the seasonality found in the Hadley cell changes [Hu and $\mathrm{Fu}$ (2007)] do not as clearly appear in the cloud faction changes analyzed here. One may see the storm tracks as being pushed poleward by the expanding Hadley cell, but the storm track shifts may also be seen as a separate process, caused by the changes in thermal structure of the atmosphere in the midlatitudes, as discussed e.g. by Yin (2005) and as demonstrated here by changes in the mid-tropospheric temperature field.

On a seasonal time scale, storm tracks move poleward in spring/summer when the pole-to-equator temperature gradient is weaker and vice versa [Chang et al. (2002)]. If the same processes determine the variability on interannual and decadal timescale, an asymmetry between the two hemispheres may be expected. The meridional signature of global warming indicates a weakening of the meridional temperature gradient in the $\mathrm{NH}$ and a strengthening in the $\mathrm{SH}$. Such interhemispheric asymmetry can be traced in the reanalysis temperature field, but is not supported by our analysis of cloudiness, suggesting that for the shift in storm track position, the magnitude of the meridional temperature gradient is not as important as its position.

\section{Discussion and conclusions}

ISCCP satellite observations suggest that the midlatitude bands of maximum storm track cloudiness over the northern and southern hemisphere Pacific and Atlantic oceans, shift poleward and narrow during the years 1983-2008. The magnitude of the shift is much larger in the NH Atlantic, but shortcomings in the ISCCP data particularly prevent us from drawing firm conclusions about this region.

The shifts seen support previous indications from climate models, of poleward shifts of the storm tracks in response to global warming. But a comparison with 20 CMIP3 GCMs shows a consistent discrepancy, with ISCCP 
data suggesting larger rates of poleward shifts than the models, even under strongly increasing $\mathrm{CO}_{2}$ scenarios.

The regional changes in the original ISCCP data are likely artificially exaggerated, mainly due to a dependence of cloud retrieval on satellite viewing angle. Different approaches to account for this spuriousness; excluding specifically problematic regions ( $\mathrm{NH}$ Atlantic), adjusting for a linear dependence on regional mean viewing angle and excluding specific cloud types (optically thin clouds) are investigated. These approaches all reduce the changes in cloudiness, and when thin clouds are excluded a consistent poleward shift in all regions is no longer evident.

All suggested methods are imperfect, but the VZAcorrection and the thin-cloud exclusion method may both introduce new additional errors when used to modify the data. We therefore consider the selective region approach the most direct, and preferable one, bearing in mind that the estimates from it may still be exaggerated for all regions, and using the two other data-modification methods to indicate possible ranges of cloud changes.

Hereby, the NH Atlantic must be excluded, or viewed with particular caution. From our analysis, in combination with previous studies on problems with the ISCCP data used, it is clear that the stronger shift and reduction in the NH Atlantic storm track cloudiness is exaggerated by data artefacts. However, the general similarity in patterns and in variations in different cloud types between the NH Atlantic and the regions where the satellite data can be considered more trustworthy gives us reason to believe that there is a real shift in this region too, hidden by the spurious variability in the data. The western part of the NH Pacific, and smaller areas in each storm track region show similar changes, supporting the credibility of the results for the other storm track regions.

The changes in cloudiness are consistent with independent satellite measured changes in radiation. Although the causes of the changes in storm track extent and location are yet not clear, we can also show their consistency with poleward shifts in central position of meridional temperature gradient, from re-analysis data.

The cloudiness changes also affect the regional cloud radiative forcing. These effects are crudely quantified by relating cloud fraction anomalies to radiative flux anomalies. The total cloud fraction, which is positively correlated with the reflected SW radiation at TOA, decreases over the period studied (except when thin clouds are excluded), whereas the upper (high+middle) cloud fraction, which is negatively correlated with the outgoing LW radiation at TOA, increases. Therefore, SW and LW cloud radiative effects are found to act together to contribute to warming, or positive cloud feedback of significant magnitude. The regional forcing estimates may amount to as much as $6 \mathrm{~W} \mathrm{~m}^{-2}$, if the original ISCCP data for all regions are trusted. The selective regional approach taken excludes the highest forcing estimates (for the NH Atlantic), linearly adjusting the data for VZA-dependence further reduces the estimates for all regions, and excluding optically thin clouds further reduces, and in the case of the NH Pacific even reverses the sign of the forcing estimate. The resulting ranges are for the $\mathrm{NH}$ Pacific $4.1--0.9 \mathrm{~W} \mathrm{~m}^{-2}$, NH Atlantic $6.1-2.1 \mathrm{~W} \mathrm{~m}^{-2}$, SH Pacific $5.1-0.9 \mathrm{~W} \mathrm{~m}^{-2}$, NH Atlantic $3.4-0.8 \mathrm{~W} \mathrm{~m}^{-2}$.

The shift in storm track position, even with no accompanying decrease in total cloud cover should also lead to a positive radiative anomaly, as there will be larger reflectivity in regions with less insolation (i.e. further poleward), as discussed e.g. by Tsushima et al. (2006), but this effect is not explicitly quantified here.

Results from 20 CMIP3 models are consistent with positive cloud feedback on a global scale. Among the seven models that show agreement with the original and the VZA-adjusted observations through poleward shift of storm tracks in all four regions studied, the response to increasing $\mathrm{CO}_{2}$ is in all but one case a statistically significant decrease in global mean total cloud fraction. The models with comparatively low climate sensitivity also tend to reproduce the poleward shift of the storm tracks less well, and none of the models with equilibrium climate sensitivity below $3 \mathrm{~K}$ simulate a statistically significant poleward shift in all four regions.

Potential aerosol effects on the storm tracks cannot be established and inter-hemispheric symmetry in cloud response, despite great asymmetry in aerosol loading rather suggests that aerosols do not play a critical role for the changes seen. Particularly, it is argued that the previously proposed effect of Asian aerosol on deep convective clouds in the NH Pacific cannot be evinced, but these issues require further investigation.

In general, more data, particularly longer, and more reliable, time series of cloud fraction and cloud properties and types as well as radiative fluxes are desired, to render more statistical significance to the analysis, and to further support or challenge the conclusions drawn. Our analysis also makes evident that ISCCP data must be used and construed with caution, not only when analyzing global mean trends, but also for regional variability analysis. There may be issues remaining with regard to the satellite data, but we present possible ways to look at these problems.

Acknowledgments This work was funded by the National Science Foundation, through the Atmospheric Science Division, ATM0721142. We acknowledge the modeling groups, the Program for Climate Model Diagnosis and Intercomparison (PCMDI) and the WCRP's Working Group on Coupled Modelling (WGCM) for their roles in making available the WCRP CMIP3 multi-model dataset. Support of this dataset is provided by the Office of Science, U.S. Department of Energy. CRU data are obtained from 
http://www.metoffice.gov.uk/hadobs, ERA data from the ECMWF Data Server, ERBE and CERES data from the Atmospheric Science Data Center at NASA Langley Research Center, ISCCP data from http://isccp.giss.nasa.gov/products/onlineData.html.

\section{Appendix}

See Tables 5, 6 and Figs. 9, 10.
Fig. 9 Global ocean aveage ISCCP total cloud fraction anomaly (solid line, left $y$-axis), and $\mu=1 / \cos (V Z A)$ (dashed line, right $y$-axis) anomaly. Monthly mean values 1983-2008, smoothed with a 3 month running average. Explained variance $\left(R^{2}\right)$ is 0.5
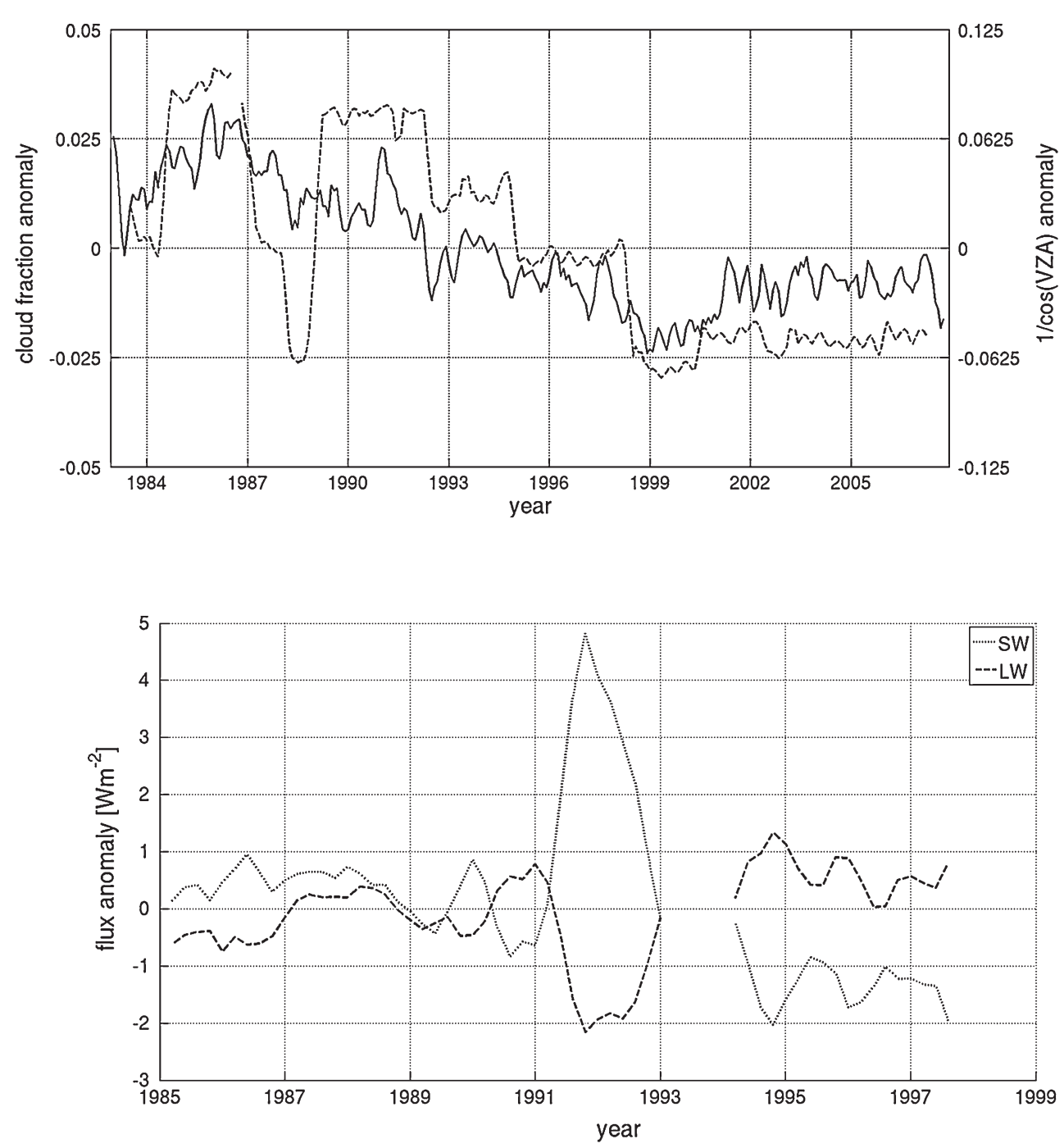

year
Fig. 10 Deseasonalized monthly mean anomalies of reflected SW (dotted line) and outgoing LW (dashed line) at TOA from ERBE WFOV. Data shown for ocean only, averaged between $60^{\circ} \mathrm{S}$ and $60^{\circ} \mathrm{N}$ and smoothed with a 3 month running average

Table 5 Correlation coefficients (r) for relations between SW flux and SW CRF and LW flux and LW CRF on global scale (ocean only) and for four storm track regions, using deseasonalized monthly mean anomalies from CERES ES4 (March 2000-February 2010) and ERBE S4G (November 1984-February 1991) respectively

\begin{tabular}{|c|c|c|c|c|c|c|c|c|c|}
\hline \multirow[b]{2}{*}{ SW-SW CRF } & \multirow{2}{*}{$\frac{\text { Global }}{r}$} & \multicolumn{2}{|c|}{ NH Pacific } & \multicolumn{2}{|c|}{ NH Atlantic } & \multicolumn{2}{|c|}{ SH Pacific } & \multicolumn{2}{|c|}{ SH Atlantic } \\
\hline & & $r$ & $b$ & $r$ & $b$ & $r$ & $b$ & $r$ & $b$ \\
\hline CERES ES4 & -0.95 & -0.98 & -1.07 & -0.98 & -1.02 & -0.99 & -1.04 & -0.92 & -1.02 \\
\hline ERBE S4G & -0.78 & -0.95 & -0.99 & -0.92 & -0.88 & -0.90 & -0.99 & -0.92 & -0.92 \\
\hline LW-LW CRF & $r$ & $r$ & $b$ & $r$ & $b$ & $r$ & $b$ & $r$ & $b$ \\
\hline CERES ES4 & -0.65 & -0.89 & -1.08 & -0.94 & -1.11 & -0.89 & -0.96 & -0.78 & -0.91 \\
\hline ERBE S4G & -0.43 & -0.88 & -1.13 & -0.87 & -1.14 & -0.79 & -0.81 & -0.78 & -0.83 \\
\hline
\end{tabular}


Table 6 Correlation coefficients $(r)$ for deseasonalized monthly mean anomalies of SW and LW radiative fluxes and cloud fraction, and corresponding linear regression coefficients $(b)$ from various combinations of satellite data sets, for global ocean and four storm track regions

\begin{tabular}{|c|c|c|c|c|c|c|c|c|c|}
\hline \multirow[b]{2}{*}{ SW-total cloud } & \multirow{2}{*}{$\begin{array}{l}\text { Global } \\
r\end{array}$} & \multicolumn{2}{|c|}{ NH Pacific } & \multicolumn{2}{|c|}{ NH Atlantic } & \multicolumn{2}{|c|}{ SH Pacific } & \multicolumn{2}{|c|}{ SH Atlantic } \\
\hline & & $r$ & $b$ & $r$ & $b$ & $r$ & $b$ & $r$ & $b$ \\
\hline CERES $^{a}$-MODIS $^{\mathrm{a}}$ & 0.8 & 0.8 & 1.1 & 0.9 & 1.1 & 0.9 & 1.2 & 0.8 & 1.2 \\
\hline CERES $^{\mathrm{b}}$-MODIS ${ }^{\mathrm{a}}$ & 0.6 & 0.8 & 1.2 & 0.8 & 1.1 & 0.8 & 1.2 & 0.8 & 1.2 \\
\hline CERES $^{\mathrm{a}}$-MODIS ${ }^{\mathrm{b}}$ & 0.7 & 0.8 & 1.4 & 0.8 & 1.2 & 0.9 & 1.6 & 0.8 & 1.4 \\
\hline CERES $^{\mathrm{b}}$-MODIS ${ }^{\mathrm{b}}$ & 0.7 & 0.8 & 1.5 & 0.8 & 1.2 & 0.9 & 1.7 & 0.8 & 1.4 \\
\hline CERES $^{\mathrm{a}}$-ISCCP & 0.6 & 0.7 & 1.5 & 0.8 & 1.1 & 0.7 & 1.1 & 0.8 & 1.3 \\
\hline CERES $^{\mathrm{b}}$-ISCCP & 0.3 & 0.7 & 1.5 & 0.8 & 1.1 & 0.6 & 0.9 & 0.7 & 1.4 \\
\hline ERBE-ISCCP & 0.2 & 0.6 & 1.4 & 0.4 & 0.4 & 0.5 & 1.0 & 0.5 & 0.7 \\
\hline LW-total cloud & $r$ & $r$ & $b$ & $r$ & $b$ & $r$ & $b$ & $r$ & $b$ \\
\hline CERES $^{\mathrm{a}}$-MODIS ${ }^{\mathrm{a}}$ & $\mathbf{0}$ & -0.4 & -0.4 & -0.4 & -0.5 & -0.5 & -0.4 & -0.3 & -0.3 \\
\hline CERES $^{\mathrm{b}}$-MODIS ${ }^{\mathrm{a}}$ & -0.1 & -0.4 & -0.4 & -0.5 & -0.6 & -0.5 & -0.4 & -0.4 & -0.3 \\
\hline CERES $^{\mathrm{a}}$-MODIS ${ }^{\mathrm{b}}$ & -0.1 & -0.5 & -0.6 & -0.5 & -0.7 & -0.4 & -0.5 & -0.3 & -0.3 \\
\hline CERES $^{\mathrm{b}}$-MODIS ${ }^{\mathrm{b}}$ & -0.1 & -0.5 & -0.6 & -0.6 & -0.7 & -0.5 & -0.5 & -0.3 & -0.3 \\
\hline CERES $^{\mathrm{a}}$-ISCCP & 0.1 & -0.3 & -0.2 & -0.5 & -0.5 & -0.3 & -0.3 & -0.3 & -0.3 \\
\hline CERES $^{\text {b-ISCCP }}$ & $\mathbf{0}$ & -0.2 & -0.3 & -0.6 & -0.7 & -0.4 & -0.4 & -0.3 & -0.3 \\
\hline ERBE-ISCCP & -0.6 & -0.5 & -0.8 & -0.7 & -0.7 & -0.6 & -1.0 & -0.5 & -0.6 \\
\hline LW-ice cloud & $r$ & $r$ & $b$ & $r$ & $b$ & $r$ & $b$ & $r$ & $b$ \\
\hline CERES $^{\mathrm{a}}$-MODIS ${ }^{\mathrm{a}}$ & -0.5 & -0.8 & -1.0 & -0.9 & -0.9 & -0.8 & -0.7 & -0.7 & -0.6 \\
\hline CERES $^{\mathrm{b}}$-MODIS ${ }^{\mathrm{a}}$ & -0.5 & -0.8 & -1.0 & -0.9 & -0.9 & -0.8 & -0.7 & -0.6 & -0.5 \\
\hline LW- upper cloud & $r$ & $r$ & $b$ & $r$ & $b$ & $r$ & $b$ & $r$ & $b$ \\
\hline CERES $^{\mathrm{a}}$-ISCCP & 0.1 & -0.3 & -0.2 & -0.7 & -0.4 & -0.3 & -0.2 & -0.3 & -0.1 \\
\hline CERES $^{\text {b-ISCCP }}$ & $\mathbf{0}$ & -0.5 & -0.3 & -0.8 & -0.5 & -0.3 & -0.1 & -0.2 & -0.1 \\
\hline ERBE-ISCCP & -0.2 & -0.6 & -0.7 & -0.7 & -0.6 & -0.6 & -0.5 & -0.5 & -0.4 \\
\hline
\end{tabular}

MODIS $^{\mathrm{a}}$ is total cloud fraction derived from retrieved cloud optical properties and MODIS ${ }^{\mathrm{b}}$ is total cloud fraction derived from retrieved cloud mask; CERES ${ }^{\mathrm{a}}$ is CERES SSF, CERES ${ }^{\mathrm{b}}$ is CERES ES4; ERBE is ERBE S4G. Correlations not significant at a 95\% level and regression coefficients whose $95 \%$ confidence intervals include 0 in bold, significant correlations and regression coefficients on italics. Correlation coefficients greater than 0.5 , and corresponding regression coefficients, in bolditalic

\section{References}

Barkstrom BR (1984) The earth radiation budget experiment (ERBE). Bull Amer Meteor Soc 65:1170-1185

Barkstrom BR, Smith GL (1986) The earth radiation budget experiment: science and implementation. Rev Geophys 24:379-390

Bengtsson L, Hodges KI, Roeckner E (2006) Storm tracks and climate change. J Clim 19:3518-3543

Bond TC, Bhardwaj E, Dong R, Jogani R, Jung S, Roden C, Streets DG, Fernandes S, Trautmann N (2007) Historical emissions of black and organic carbon aerosol from energy-related combustion, 1850-2000. Global Biogeochem Cycles 21:GB2018

Brest CL, Rossow WB, Roiter M (1997) Update of radiance calibrations for ISCCP. J Atmos Ocean Tech 14:1091-1109

Brohan P, Kennedy JJ, Harris I, Tett SFB, Jones PD (2006) Uncertainty estimates in regional and global observed temperature changes: a new dataset from 1850. J Geophys Res 111:D12106

Chang EKM, Lee S, Swanson KL (2002) Storm track dynamics. J Clim 15:2163-2183
Clement AC, Burgman R, Norris JR (2009) Observational and model evidence for positive low-level cloud feedback. Science 325:460

Evan AT, Heidinger AK, Vimont DJ (2007) Arguments against a physical long-term trend in global ISCCP cloud amounts. Geophys Res Lett 34:L04701

Field PR, Wood R (2007) Precipitation and cloud structure in midlatitude cyclones. J Clim 20:233-254

Field PR, Gettleman A, Neale RB, Wood R, Rasch PJ, Morrison H (2008) Midlatitude cyclone compositing to constrain climate model behavior using satellite obserations. J Clim 21:5887-5903

Fischer-Bruns I, von Storch H, Gonzalez-Rouco JF, Zorita E (2005) Modelling the variability of midlatitude storm activity on decadal to century time scales. Clim Dyn 25:461-476

Fyfe J (2003) Extratropical southern hemisphere cyclones: harbingers of climate change?. J Clim 16:2802-2805

Geng Q, Sugi M (2003) Possible change of extratropical cyclone activity due to enhanced greenhouse gases and sulfate aerosolsstudy with a high-resolution AGCM. J Clim 16:2262-2274

Hall NMJ, Hoskins BJ, Valdes PJ, Senior CA (1994) Storm tracks in a high-resolution GCM with doubled carbon dioxide. Q J Royal Meteorol Soc 120:1209-1230 
$\mathrm{Hu}$ Y, Fu Q (2007) Observed poleward expansion of the Hadley circulation since 1979. Atmos Chem Phys 7:5229-5236

Hurrell JW, Deser C (2010) North Atlantic climate variability: the role of the North Atlantic Oscillation. J Mar Syst 79:253-271

IPCC (2007) Climate change 2007: the scientific basis. Contribution of working group 1 to the fourth assessment report of the intergovernmental panel on climate change. In: Solomon S, Qin D, Manning M, Chen Z, Marquis M, Averyt KB, Tignor M, Miller HL (eds) Cambridge University Press, Cambridge. p 996

Johanson CM, Fu Q (2009) Hadley cell widening: model simulations versus observations. J. Clim 22:2713-2725

King MD, Kaufman YJ, Menzel WP, Tanre D (1992) Remote sensing if cloud, aerosol, and water vapour properties from the moderate resolution imaging spectrometer (MODIS). IEEE Trans Geosci Remote Sens 30:2-27

Knapp KR (2007) Calibration assessment of ISCCP geostationary infrared observations using HIRS. J Atmos Oceanic Technol 25:183-195

Loeb NG, Wielicki BA, Rose FG, Doelling DR (2007) Variability in global top-of-atmosphere shortwave radiation between 2000 and 2005. Geophys Res Lett 34:L03704

Lu J, Vecchi GA, Reichler T (2007) Expansion of the Hadley cell under global warming. Geophys Res Lett 34:L06805

Massie ST, Torres O, Smith SJ (2004) Total ozone mapping spectrometer (TOMS) observations of increases in Asian aerosol in winter from 1979 to 2000. J Geophys Res 109:D18211

McCabe G, Martyn CP, Serreze MC (2001) Trends in northern hemisphere surface cyclone frequency and intensity. J Clim 14:2763-2768

Meehl GA, Covey C, Delworth T, Latif M, McAveny B, Mitchell JFB, Stouffer RJ, Taylor KE (2007) The WCRP CMIP3 multimodel dataset: a new era in climate change research. Bull Amer Meteor Soc 88:1383-1394

Minnis P (1989) Viewing zenith angle dependence of cloudiness determined from coincident GOES east and GOES west data. J Geophys Res 94(D2):2303-2320

Norris JR (2000) What can cloud observations tell us about climate variability?. Space Sci Rev 94:375-380

Norris JR (2005) Multidecadal changes in near-global cloud cover and estimated cloud cover radiative forcing. J Geophys Res 110:D08206

O'Gorman PA (2010) Understanding the varied response of the extratropical storm tracks to climate change. Proc Natl Acad Sci USA 107(45):19176-19180

Ohara T, Akimoto H, Kurokawa J, Horii N, Yamaji K, Yan X, Hayasaka T (2007) An Asian emission inventory of anthropogenic emission sources for the period 19802020. Atmos Chem Phys 7:4419-4444
Ramanathan V, Cess RD, Harrison EF, Minnis P, Barkstrom BR, Ahmad E, Hartmann D (1989) Cloud-radiative forcing and climate: results from the earth radiation budget experiment. Science 243:57-63

Rossow WB, Schiffer RA (1991) ISCCP cloud data products. Bull Amer Meteor Soc 72:2-20

Rossow WB, Schiffer RA (1999) Advances in understanding clouds from ISCCP. Bull Amer Meteor Soc 80:2261-2287

Smith SJ, Pitcher H, Wigley TML (2001) Global and regional anthropogenic sulfur dioxide emissions. Global Planet Change 29:99-119

Streets DG, Yu C, Wu Y, Chin M, Zhao Z, Hayasaka T, Shi G (2008) Aerosol trends over China 1980-2000. Atmos Res 88:174-182

Tselioudis G, Tromeur E, Rosow WB, Zerefos CS (2010) Decadal changes in tropical convection suggest effects on stratospheric water vapour. Geophys Res Lett 37:L14806

Tsushima Y, Emori S, Ogura T, Kimoto M, Webb MJ, Williams KD, Ringer MA, Soden BJ, Li B, Andronova N (2006) Importance of the mixed-phase cloud distribution in the control climate for assessing the response of clouds to carbon dioxide increase: a multi-model study. Clim Dyn 27:113-126

Uppala SM et al (2005) The ERA-40 re-analysis. Q J Roy Meteor Soc 131:2961-3012

Wang XL, Swail VR, Zwiers FW (2006) Climatology and changes of extratropical cyclone activity: comparison of ERA-40 with NCEP-NCAR reanalysis for 1958-2001. J Clim 19:3145-3166

Weaver CP, Ramanathan V (1997) Relationships between large-scale vertical velocity, static stability, and cloud radiative forcing over northern hemisphere extratropical oceans. J Clim 10:2871-2887

Wielicki BA, Barkstrom BR, Harrison EF, Lee RB III, Smith GL, Cooper JE (1996) Clouds and the earth's radiant energy system (CERES): an earth observing system experiment. Bull Amer Meteor Soc 77:853-868

Yin J (2005) A consistent poleward shift of the storm tracks in simulations of the 21st century climate. Geophys Res Lett 32:L18701

Zhang Y-C, Rossow WB, Lacis AA, Oinas V, Mishchenko MI (2004) Calculation of radiative fluxes from the surface to top of atmosphere based on ISCCP and other global data sets: Refinements of the radiative transfer model and the input data. J Geophys Res 109:D19105

Zhang R, Li G, Fan J, Wu DL, Molina MJ (2007) Intensification of Pacific storm track linked to Asian pollution. Proc Natl Acad Sci USA 104(13):5295-5299

Zhu A, Ramanathan V, Li F, Kim D (2007) Dust plumes over the Pacific, Indian, and Atlantic oceans: climatology and radiative impact. J Geophys Res 112:D16208 